\title{
Separation of Acute Desensitization and Long-Term Tolerance of $\mu$-Opioid Receptors Is Determined by the Degree of C-Terminal Phosphorylation $\$$
}

\author{
Seksiri Arttamangkul, Emily R. Leff, Omar Koita, William T. Birdsong, ${ }^{1}$ and John T. Williams \\ Vollum Institute, Oregon Health \& Science University, Portland, Oregon
}

Received May 28, 2019; accepted August 2, 2019

\begin{abstract}
Phosphorylation of sites on the $C$ terminus of the $\mu$-opioid receptor (MOR) results in the induction of acute desensitization that is thought to be a precursor for the development of longterm tolerance. Alanine mutations of all 11 phosphorylation sites on the $\mathrm{C}$ terminus of MORs almost completely abolished desensitization and one measure of tolerance in locus coeruleus neurons when these phosphorylation-deficient MORs were virally expressed in MOR knockout rats. In the present work, we identified specific residues that underlie acute desensitization, receptor internalization, and tolerance and examined four MOR variants with different alanine or glutamate mutations in the $\mathrm{C}$ terminus. Alanine mutations in the sequence between amino acids 375 and 379 (STANT-3A) and the sequence between amino acids 363 and 394 having four additional alanine substitutions (STANT $+7 A$ ) reduced desensitization and two measures of long-term tolerance. After chronic morphine treatment, alanine mutations in the sequence between 354 and 357 (TSST-4A) blocked one measure of long-term tolerance (increased acute desensitization and slowed recovery from desensitization) but did not change a second (decreased sensitivity to morphine). With the expression of receptors having glutamate
\end{abstract}

substitutions in the TSST sequence (TSST-4E), an increase in acute desensitization was present after chronic morphine treatment, but the sensitivity to morphine was not changed. The results show that all 11 phosphorylation sites contribute, in varying degrees, to acute desensitization and long-term tolerance. That acute desensitization and tolerance are not necessarily linked illustrates the complexity of events that are triggered by chronic treatment with morphine.

\section{SIGNIFICANCE STATEMENT}

In this work, we showed that the degree of phosphorylation on the $\mathrm{C}$ terminus of the $\mu$-opioid receptor alters acute desensitization and internalization, and in measures of long-term tolerance to morphine. The primary conclusion is that the degree of phosphorylation on the 11 possible sites of the $\mathrm{C}$ terminus has different roles for expression of the multiple adaptive mechanisms that follow acute and long-term agonist activation. Although the idea that acute desensitization and tolerance are intimately linked is generally supported, these results indicate that disruption of one phosphorylation cassette of the $\mathrm{C}$ terminus TSST (354-357) distinguishes the two processes.

\section{Introduction}

The $\mathrm{C}$ terminus of the $\mu$-opioid receptor (MOR) has multiple phosphorylation sites that are implicated in the mechanisms of receptor desensitization and trafficking. Two cassettes on the MOR C terminus were efficiently phosphorylated after treatment with a potent agonist (Wang et al., 2002; Doll et al., 2011; Lau et al., 2011; Chen et al., 2013; Just et al., 2013; Miess et al., 2018). When the residues from 375 to 379 (STANT) were mutated to alanine, arrestin recruitment and internalization were blocked (Lau et al., 2011). Residues in the second cassette, ranging from 354 to 357 (TSST), were also efficiently phosphorylated, but internalization was unaffected.

This work was supported by National Institutes of Health Grants JTW RO1 DA08163, WTB DA043779, and ERL T32DA007262.

${ }^{1}$ Current affiliation: Department of Pharmacology, University of Michigan, Ann Arbor, Michigan.

https://doi.org/10.1124/mol.119.117358.

S This article has supplemental material available at molpharm. aspetjournals.org.
The electrophysiological consequences of alanine mutations in each cassette were examined using viral expression in neurons of the thalamus and locus coeruleus (LC) in MOR knockout mice (Birdsong et al., 2015). The results indicated that mutations of all serine and threonine residues in the individual cassettes had small effects on acute desensitization. With mutations of the residues in both cassettes, acute desensitization was reduced (Birdsong et al., 2015; Yousuf et al., 2015). The functional consequences of mutations in other potential phosphorylation sites (S-363, T-370, -383, and -394) have not been examined. Phosphorylation of S-363 is thought to be constitutive or protein kinase C-dependent, whereas phosphorylation of T-370 can be induced by agonists (reviewed in Williams et al., 2013)). There is no evidence showing phosphorylated forms at T-383 and T-394 by mass spectrometry (Lau et al., 2011). Acute desensitization measured in LC neurons was almost completely eliminated in a knock-in mouse in which all 11 Cterminus phosphorylation sites or the 10 sites minus T-394 were mutated to alanine (Kliewer et al., 2019). Likewise, acute desensitization and the 
development of long-term tolerance were blocked after viral expression of phosphorylation-deficient MORs in LC neurons of MOR knockout rats (Arttamangkul et al., 2018).

In the present study, we examined acute desensitization in slices from untreated and morphine treate animals (MTA) in each of four mutant MORs: STANT-3A (S375-T379 to AAANA), STANT-7A (S363A, T370A, 375-379 to AAANA, T383A, T394A), TSST-4A (354-375 to AAAA), and TSST-4E (354-357 to EEEE). Each receptor contained an N terminus GFP tag that, when coupled with a fluorescent nanobody, was used to assess trafficking (Arttamangkul et al., 2018). Internalization of the STANT-3A and STANT-7A mutant receptors was blocked, as previously found in human embryonic kidney cells (Birdsong et al., 2015). Acute desensitization was maintained in the STANT-3A and TSST mutant receptors and blocked in the STANT-7A receptors. Two measures of tolerance were examined after chronic treatment. First, the current induced by morphine was reduced in experiments with wild-type and TSST-4A receptors, whereas no change occurred in slices expressing the STANT-3A and TSST-4E receptors. The second assay used the time course of recovery from acute desensitization as a measure of the development of tolerance. The recovery from acute desensitization was decreased in slices expressing wild-type receptors after chronic morphine treatment (Dang and Williams, 2004; Quillinan et al., 2011; Arttamangkul et al., 2018); but in slices expressing each of the mutant MORs, recovery was not different in untreated and MTAs. The results suggest that phosphorylation of the $\mathrm{C}$ terminus of the MOR contribute to prolongation of the recovery from desensitization that is a hallmark of tolerance found in experiments from wild-type animals.

\section{Materials and Methods}

\section{Drugs}

Morphine sulfate and morphine alkaloid were obtained from the National Institute on Drug Abuse, Neuroscience Center (Bethesda, MD). Naloxone was purchased from Abcam (Cambridge, MA), MK-801 from Hello Bio (Princeton, NJ), and UK14304 tartrate from Tocris (Bio-Techne Corp., Minneapolis, MN). Potassium methanesulfonate was from Alfa Aesar (Ward Hill, MA). [Met $\left.{ }^{5}\right]$ enkephalin (ME) was from Sigma-Aldrich (St. Louis, MO).

Morphine alkaloid was converted to salt form with $0.1 \mathrm{M} \mathrm{HCl}$ and made up a stock solution in water. The working solution was diluted in artificial cerebrospinal fluid (ACSF) and applied by superfusion. Naloxone $(1 \mathrm{mM})$ was dissolved in water, diluted to $1 \mu \mathrm{M}$ in ACSF and applied by superfusion. Bestatin $(10 \mu \mathrm{M})$ and thiorphan $(1 \mu \mathrm{M})$ were included in solutions containing ME to limit peptidase induced breakdown.

\section{Animals}

All animal experiments were conducted in accordance with the National Institutes of Health guidelines and with approval from the Institutional Animal Care and Use Committee of the Oregon Health \& Science University (Portland, OR). Adult (180-300 g or 5 to 6 weeks) male and female Sprague-Dawley rats were obtained from Charles River Laboratories (Wilmington, MA). MOR-knockout SpragueDawley rats were obtained from Horizon (St. Louis, MO). Homozygous animals were bred in-house.

\section{Microinjection Protocol}

Microinjections of virus into the LC were carried out as previously described (Arttamangkul et al., 2018). MOR knockout animals (24-30 days) were anesthetized with isofluorane (Terrell, Piramal Clinical
Care, Inc., Bethlehem, PA) and placed in a stereotaxic frame. Viral particles containing adeno-associated virus type 2 for the expression of mutant MORs (STANT-3A, AAV2-CAG-SS-GFP-MOR-STANTWPRE-SV40pA, $2.06 \times 10^{13} \mathrm{vg} / \mathrm{ml}$ ), (STANT-7A, AAV2-CAG-SSGFP-MOR- STANT-7A -WPRE-SV40pA, $2.06 \times 10^{13} \mathrm{vg} / \mathrm{ml}$ ), (TSST-4A AAV2-CAG-SS-GFP-MOR-TSST-4A-WPRE-SV40pA, $2.06 \times 10^{13}$ $\mathrm{vg} / \mathrm{ml}$ ), and (TSST-4E, AAV2-CAG-SS-GFP-MOR-TSST-4EWPRE-SV40pA, $2.06 \times 10^{13} \mathrm{vg} / \mathrm{ml}$ ). The $\mathrm{N}$ terminus of each construct was fused to GFP with a human prolactin hormone signal sequence. All viruses were obtained from Virovek (Hayward, CA). Injections of $200 \mathrm{nl}$ at the rate of $0.1 \mu \mathrm{l} / \mathrm{min}$ were done bilaterally at $\pm 1.25 \mathrm{~mm}$ lateral from the midline and $-9.72 \mathrm{~mm}$ from the bregma at a depth of $6.95 \mathrm{~mm}$ from the top of the skull using computer controlled stereotaxic Neurostar (Tubingen, Germany). Experiments were carried out 2-4 weeks after the injection.

\section{Animal Treatment Protocols}

Rats (5 to 6 weeks) were treated with morphine sulfate using osmotic pumps (2ML1; Alzet, Cupertino, CA) as described previously (Quillinan et al., 2011). Rats were anesthetized, and the pumps were implanted subcutaneously.

\section{Tissue Preparation}

Horizontal slices containing LC neurons were prepared as described previously (Williams and North, 1984). Briefly, rats were killed, and the brain was removed, blocked, and mounted in a vibratome chamber (VT 1200S; Leica, Nussloch, Germany). Horizontal slices $(250-300 \mu \mathrm{m})$ were prepared in warm $\left(34^{\circ} \mathrm{C}\right) \mathrm{ACSF}$ (in millimolars): $126 \mathrm{NaCl}, 2.5 \mathrm{KCl}, 1.2 \mathrm{MgCl}_{2}, 2.6 \mathrm{CaCl}_{2}, 1.2$ $\mathrm{NaH}_{2} \mathrm{PO}_{4}, 11$ D-glucose and $21.4 \mathrm{NaHCO}_{3}$, and 0.01 (+) MK-801 (equilibrated with 95\% O2/5\% CO2; Matheson, Basking Ridge, NJ). Slices were kept in solution with (+)MK-801 for at least 30 minutes and then stored in glass vials with oxygenated $\left(95 \% \quad \mathrm{O}_{2} / 5 \% \mathrm{CO}_{2}\right)$ $\mathrm{ACSF}$ at $34^{\circ} \mathrm{C}$ until used.

\section{Electrophysiology}

Slices were hemisected and transferred to the recording chamber, which was superfused with $34^{\circ} \mathrm{C}$ ACSF at a rate of $1.5-2 \mathrm{ml} / \mathrm{min}$. Whole-cell recordings were made from LC neurons with an Axopatch$1 \mathrm{D}$ amplifier in voltage-clamp mode $\left(V_{\text {hold }}=-60 \mathrm{mV}\right)$. Recording pipettes (1.7-2.1 M $\Omega$; World Precision Instruments, Saratosa, FL) used an internal solution of (in millimolars): 115 potassium methanesulfonate or potassium methyl sulfate, $20 \mathrm{KCl}, 1.5 \mathrm{MgCl}_{2}, 5$ HEPES(K), 10 BAPTA, 2 Mg-ATP, 0.2 Na-GTP (pH 7.4), and 275-280 mOsM. Recordings where the series resistance was $<15$ $\mathrm{M} \Omega$ were terminated. Data were collected at $400 \mathrm{~Hz}$ with PowerLab (Chart Version 5.4.2; AD Instruments, Colorado Springs, CO).

\section{MOR-GFP Trafficking}

Brain slices $(240 \mu \mathrm{m})$ from the virally injected rats were prepared as previously described. Slices were visualized with an Olympus Macroview fluorescent microscope for GFP expression in the LC area and to visualize plasma membrane associated receptors slices were incubated in a solution of anti-GFP nanobody Alexa594 (Nb-A594, $10 \mu \mathrm{g} / \mathrm{ml}, 30-45$ minutes) Arttamangkul et al., 2018). Images were captured using an upright microscope (Olympus, Center Valley, PA) equipped with a custom-built two-photon apparatus and a $60 \times$ water immersion lens (LUMFI, NA1.1; Olympus). The dye was excited at 810 $\mathrm{nm}$. Data were acquired and collected using Scan Image Software (Vidrio Technologies, Leesburg, VA) (Pologruto et al., 2003). Images were taken at a magnification whereby a single neuron filled the field of view. A $z$-series of 10 sections was collected at $1-\mu \mathrm{m}$ intervals. With this protocol, the whole neuron was qualitatively compared. Drugs were applied by perfusion at the rate of $1.5 \mathrm{ml} / \mathrm{min}$. All experiments were done at $35^{\circ} \mathrm{C}$. 


\section{Data Analysis}

Analysis was performed using KaleidaGraph (Synergy Software, Reading, PA). Values are presented as mean \pm S.D. Statistical comparisons were made using unpaired $t$ tests or a two-way ANOVA, as appropriate. Comparisons with $P<0.05$ were considered significant.

\section{Results}

As in previous work, [Met] ${ }^{5}$ enkephalin (ME, 0.3 and $30 \mu \mathrm{M}$ ) was applied in each experiment. In slices from wild-type animals, the initial current amplitude induced by $\mathrm{ME}$ $(0.3 \mu \mathrm{M})$ was about $60 \%$ that induced by the saturating concentration of ME $(30 \mu \mathrm{M})$. The initial amplitude of the currents induced by $\mathrm{ME}(0.3 / 30 \mu \mathrm{M})$, measured in slices from virally expressed receptors, varied but were similar in amplitude to the currents (in picoamperes) measured in wild-type animals (Table 1, ANOVA, Dunnett's post hoc).

\section{Trafficking}

Previous results showed that virally expressed wild-type receptors were efficiently internalized during the application of $\mathrm{ME}$ (30 $\mu \mathrm{M}, 10$ minutes), whereas internalization of receptors where all phorphorylation sites on the $\mathrm{C}$ terminus were mutated to alanine was not observed (Arttamangkul et al., 2018). In the present study, we examined the internalization of the receptors with specific mutations using two-photon microscopy. Each mutant receptor had an extracellular GFP-tag such that plasma membrane-associated receptors were labeled with an anti-GFP nanobody conjugated with alexa594 (Fig. 1). A z-stack of images of single cells was collected before and after treatment of slices with $\mathrm{ME}(30 \mu \mathrm{M}$, 10 minutes). A distinct qualitative change was seen in the receptor distribution in slices with neurons expressing the TSST-4A (S/T354-357A) and TSST-4E (S/T354-357E) receptors. Before treatment with $\mathrm{ME}$, the receptors lined the plasma membrane, and after treatment with $\mathrm{ME}$, receptors were internalized, and the pattern became punctate (Fig. 1). The distribution of STANT-3A (S/T375-377A, T379A) receptors was relatively unchanged. To quantify the increase in intracellular fluorescence, the z-stack was compressed with a z-projection, and a region of interest just inside the plasma membrane of the soma was drawn (Supplemental Fig. 1). The increase in fluorescence measured in arbitrary fluorescence units (AFU) in that region of interest after treatment with ME was taken as the internalized receptors. By this rough measure, there was an increase in fluorescence with the TSST-4A (95\% confidence level $=255 \pm 168$ AFU, $n=8$ ) and TSST $-4 \mathrm{E}$ (95\% confidence level $=166 \pm 117 \mathrm{AFU}, n=7$ ) receptors and little change in the STANT-3A receptors (95\% confidence level $=31 \pm 33 \mathrm{AFU}, n=14$ ). Internalization was statistically different between the STANT-3A and both TSST-4A and TSST-4E receptors (ANOVA, Student-NewmanKeuls post hoc). Given that the alanine mutations of the STANT sequence (375-379) largely blocks arrestin recruitment, it was not surprising that the application of ME did not induce detectable internalization (Lau et al., 2011).

\section{Acute Desensitization}

The current induced by ME $(0.3 \mu \mathrm{M})$ was measured before and after a 10-minute application of $\mathrm{ME}(30 \mu \mathrm{M})$. The degree of desensitization was determined by the relative amplitude of the current induced by $\mathrm{ME}(0.3 \mu \mathrm{M})$ after a 5 -minute wash of the saturating concentration of $\mathrm{ME}$ compared with the amplitude of the initial current induced by ME $(0.3 \mu \mathrm{M})$. Recovery from desensitization was determined by measuring the current amplitude induced by $\mathrm{ME}(0.3 \mu \mathrm{M})$ over time (Fig. 2). As reported previously, recovery from desensitization in slices from wild-type animals occurred over a period of $20-35$ minutes.

\section{Coupling Efficiency Using a Partial Agonist, Morphine, to Measure Tolerance}

We compared the relative amplitudes of the currents induced by morphine and ME (Fig. 2D), and morphine (1 $\mu \mathrm{M})$ was applied until the current reached a steady state. The solution was then switched immediately to a saturating concentration of $\mathrm{ME}(30 \mu \mathrm{M})$. The ratio of the morphine/ME current was determined in slices from untreated and MTAs (Fig. 2E). This protocol takes advantage of the fact that morphine is a partial agonist and therefore is more sensitive to changes in coupling efficiency; thus, it was used as a second measure of the tolerance induced by treatment of animals with morphine (Christie et al., 1987; Levitt and Williams, 2012).

Animals were treated with morphine ( $80 \mathrm{mg} / \mathrm{kg}$ per day) for 6 to 7 days. Brain slices were prepared and maintained in morphine-free solutions such that the preparations were in a state of acute withdrawal. First, the degree of tolerance was examined using the current induced by ME $(0.3 \mu \mathrm{M})$ measured before and after application of $\mathrm{ME}(30 \mu \mathrm{M}, 10$ minutes,

TABLE 1

Summary of results

I-ME (pA), The mean amplitude of the currents induced by [Met ${ }^{5}$-enkephalin (ME) $(0.3$ and $30 \mu \mathrm{M})$ in slices from wild-type animals (WT) and each of the mutant $\mu$-opioid receptor (MORs). There was no statistical difference from WT (ANOVA, Dunnett's post hoc), indicating that the sensitivity to ME in slices from WT animals was similar to slices taken from animals expressing each of the mutant receptors. Decline (10 min/peak): Paired comparison between experiments from untreated and morphin-treated animals (MTAs) showing the decrease in current induced by ME $(30 \mu \mathrm{M})$ during a 10-minute application for each of the mutant receptors. In slices from animals expressing the TSST-4E receptors, the decline was increased in MTAs, $P<0.05$, upaired $t$ test). ME (0.3, post/pre): Paired comparison between slices from untreated and MTAs. The ratio of the current induced by ME $(0.3 \mu \mathrm{M})$ after desensitization normalized to the initial current for each of the mutant receptors. This ratio decreased in WT, STANT-7A, and TSST$4 \mathrm{E}(P<0.05$, unpaired $t$ test).

\begin{tabular}{|c|c|c|c|c|c|c|}
\hline & \multicolumn{2}{|c|}{ I- ME (pA) } & \multicolumn{2}{|c|}{ Decline (10 min/Peak) } & \multicolumn{2}{|c|}{ ME $(0.3 \mu \mathrm{M})$, Post/Pre } \\
\hline & $0.3 \mu \mathrm{M}$ & $30 \mu \mathrm{M}$ & Untreated & MTA & Untreated & MTA \\
\hline WT & $279 \pm 96(7)$ & $451 \pm 95(7)$ & $0.60 \pm 0.16$ & $0.51 \pm 0.07$ & $0.23 \pm 0.06$ & $0.13 \pm 0.08(9)$ \\
\hline STANT-3A & $259 \pm 137(9)$ & $439 \pm 134(9)$ & $0.79 \pm 0.07(7)$ & $0.78 \pm 0.08(7)$ & $0.62 \pm 0.14(10)$ & $0.56 \pm 0.15(9)$ \\
\hline STANT-7A & $290 \pm 138$ & $435 \pm 143(8)$ & $0.73 \pm 0.10(9)$ & $0.83 \pm 0.09$ & $0.82 \pm 0.15(9)$ & $0.61 \pm 0.13$ \\
\hline TSST-4A & $231 \pm 82(8)$ & $425 \pm 123(8)$ & $0.53 \pm 0.13(7)$ & $0.60 \pm 0.05(10)$ & $0.25 \pm 0.14(6)$ & $0.33 \pm 0.11$ \\
\hline TSST-4E & $286 \pm 102(7)$ & $400 \pm 123(10)$ & $0.65 \pm 0.10(7)$ & $0.49 \pm 0.13(10)$ & $0.41 \pm 0.12(7)$ & $0.18 \pm 0.13(10)$ \\
\hline
\end{tabular}



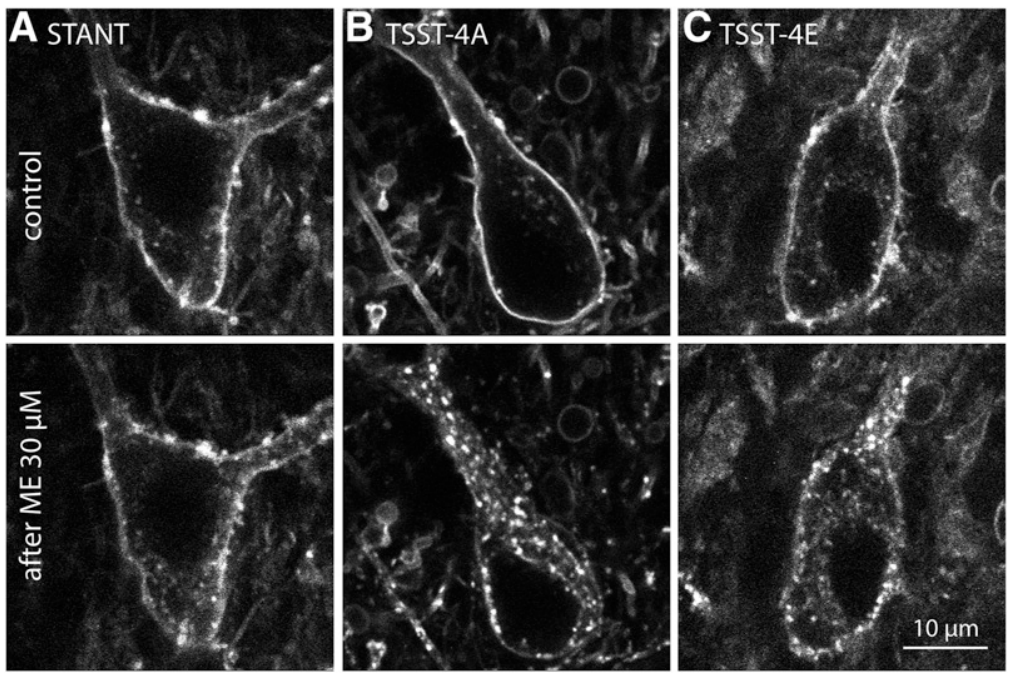

Fig. 1. Receptor imaging before and after treatment with $\mathrm{ME}$ $(30 \mu \mathrm{M}, 10 \mathrm{~min})$. An anti-GFP nanobody conjugated with Alexa594 was used to image the (A) STANT, (B) TSST-4A, and (C) TSST-4E receptors expressed in LC before (top) and after $\mathrm{ME}(30 \mu \mathrm{M}, 10 \mathrm{~min}$, bottom).

Table 1). The recovery of the current induced by $\mathrm{ME}(0.3 \mu \mathrm{M})$ was examined over 20-35 minutes. As reported previously, recovery from desensitization was slowed in slices from MTAs (Fig. 2, Dang and Williams, 2004; Quillinan et al., 2011; Arttamangkul et al., 2018). Second, the current induced by morphine $(1 \mu \mathrm{M})$ relative to the peak ME current was reduced in slices from MTAs (Fig. 2, $P<0.05$ Mann-Whitney $U$ test). This simple assay is therefore a reasonable measure of tolerance and is particularly valuable for experiments in which the viral expression of receptors in the knockout animals can be variable. A summary of the results with this measure is illustrated in the plots of the amplitude of the
B Desensitization
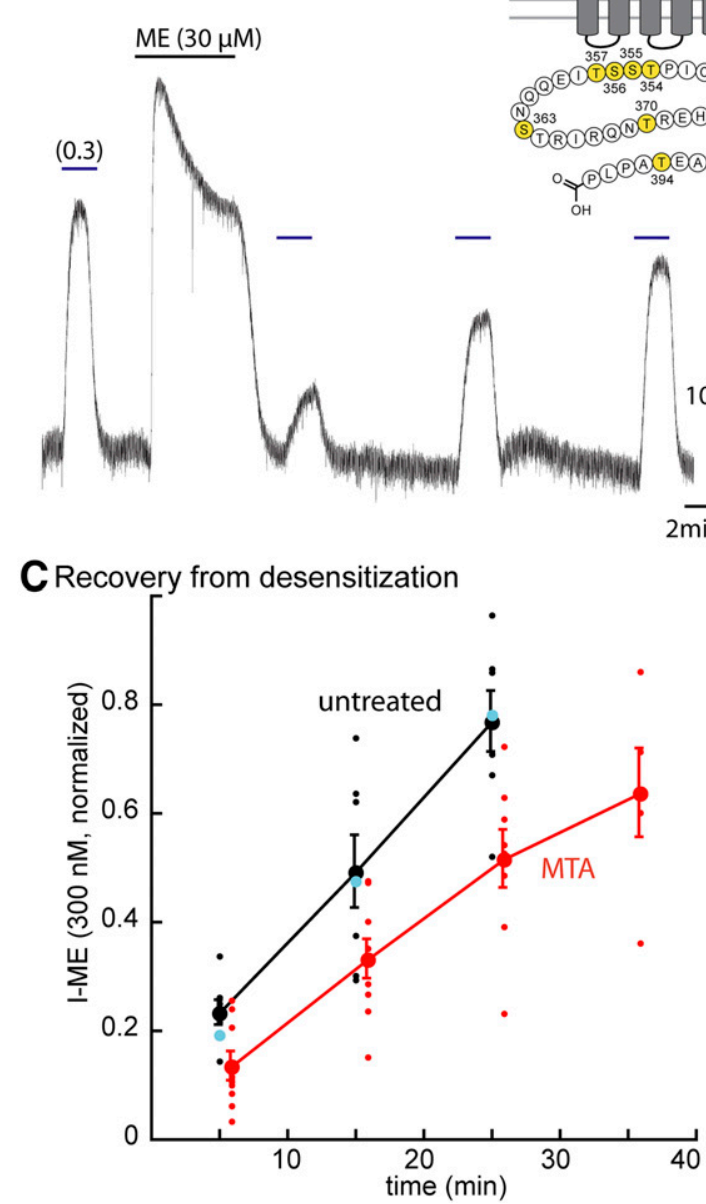
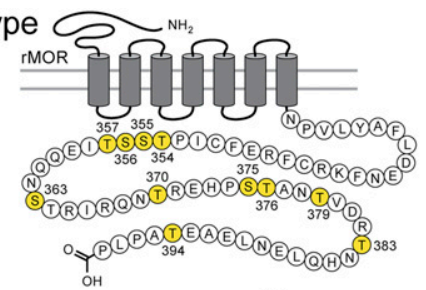

- D Morphine tolerance

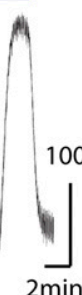

(ME 0.3) morphine (1)
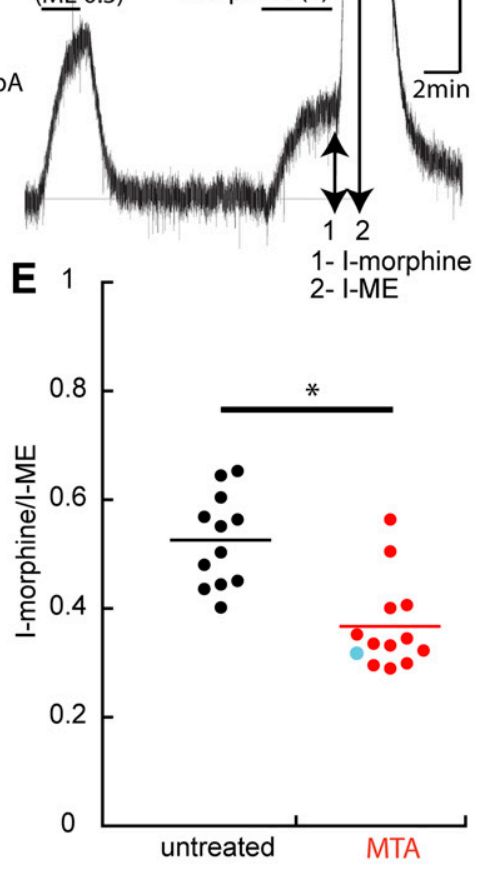

Fig. 2. Protocols used to measure two forms of tolerance using experiments carried out in wild-type animals. (A) Snake plot illustrates the phosphorylation sites on the $\mathrm{C}$ terminus (yellow: T354, S355, S356, T357, S363, T370, S375, T376, T379, T383, and T394). (B) Protocol used to determine the acute desensitization and the recovery from desensitization. (C) Summary of results showing the time course of recovery from desensitization slices from untreated (black) and MTAs (red); blue dots indicate the results from the trace in (B). (D) Trace shows the current induced by morphine (1 $\mu \mathrm{M}, 1)$ relative to that induced by $\mathrm{ME}$ (30 $\mu \mathrm{M}, 2)$. (E) Summary of the results measuring the relative current induced by morphine $(1 / 2)$ in slices from untreated animals (95\% confidence interval, $0.518 \pm 0.047)$ and MTAs (95\% confidence level $0.37 \pm 0.045$ ), indicating that the morphine-induced current is smaller in slices from MTAs. Mann-Whitney $U$ test $P<0.001$. Blue dot indicates the results from the experiment in (D). ${ }^{*} P<0.05$. 
current induced by morphine $(1 \mu \mathrm{M})$ against the current induced by $\mathrm{ME}$ (30 $\mu \mathrm{M}$, wild-type, Fig. 3A). The current induced by morphine was smaller than that induced by $\mathrm{ME}$ in slices from MTAs over a wide range of current amplitudes. The same protocols were used to measure tolerance, desensitization, and recovery from desensitization in slices taken from animals expressing each of the mutant receptors.

STANT-3A. Application of a saturating concentration of ME resulted in desensitization of the STANT-3A receptor. The decline in current during the application of $\mathrm{ME}(30 \mu \mathrm{M}$, 10 minute) was not different from that in slices from wildtype animals ( $P>0.05$, ANOVA, Dunnett's post hoc). The decrease in the current induced by $\mathrm{ME}(0.3 \mu \mathrm{M})$ after the saturating concentration was reduced compared with the wild-type (Fig. 4, $P<0.05$ ANOVA Dunnett's post hoc). This result was expected based on previous work in the mouse (Birdsong et al., 2015). The phosphorylation of S375 is thought to be an initial step leading to sequential phosphorylation events on the $\mathrm{C}$ terminus. The observation that desensitization persisted indicates that this sequence is not the sole area that underlies acute desensitization.

In slices from MTAs, the decline from the peak current induced by $\mathrm{ME}$ (30 $\mu \mathrm{M}, 10$ minutes) did not differ from that in slices from untreated animals (Table $1, P>0.05$, unpaired $t$ test). Likewise, the recovery from desensitization was the same in slices from morphine-treated and untreated animals (Fig. 4C). Thus, despite the acute desensitization seen with this receptor, no apparent induction of tolerance, as measured by an increase in desensitization or a prolongation of the time it takes to recover from desensitization, was found. The ratio of the morphine/ME current also was not different between experiments carried out in untreated and MTAs (Fig. 4E). The current amplitudes (morphine/ME) for individual cells in slices from untreated and MTAs overlapped over a range of current amplitudes. Thus, by two measures, mutation of the STANT sequence in the MOR blocked the development of tolerance.

Finally, given that treatment of the slices with $\mathrm{ME}(30 \mu \mathrm{M}$, 10 minutes) did not induce detectable internalization, one conclusion from these experiments could be that trafficking and/or arrestin recruitment is a necessary step in the development of long-term tolerance.

STANT-7A. Little or no decline was seen in the current induced by $\mathrm{ME}(30 \mu \mathrm{M})$ or the $\mathrm{ME}(0.3 \mu \mathrm{M})$ current after washout of the saturating concentration in slices expressing the STANT-7A receptor (Fig. 5; Table 1). Thus, by the inclusion of four additional alanine mutations, the STANT7A resulted in a near-complete block of desensitization, as found in STANT-3A receptors.

In slices from MTAs, a substantial increase in desensitization was noted, as determined by the decrease in the current induced by $\mathrm{ME}(0.3 \mu \mathrm{M}) 5$ minutes after washing the saturating concentration (Fig. 5; Table 1). Recovery from desensitization in slices from animals treated with morphine was near complete after washing for 10 minutes (Fig. 5). The decline from the peak current induced by $\mathrm{ME}(30 \mu \mathrm{M}$, 10 minutes) was slightly smaller than in slices from MTAs $(0.83 \pm 0.09, n=14$, untreated $=0.73 \pm 0.10, n=9, P=0.03$, unpaired $t$ test; Table 1). Chronic morphine treatment therefore resulted in a facilitation of acute desensitization measured by the decrease in current induced by $\mathrm{ME}(0.3 \mu \mathrm{M})$ that was short-lasting and not present before the morphine treatment. Thus, mutation of the four additional residues blocked acute desensitization in slices from untreated animals but did not eliminate at least one adaptive mechanism induced by chronic morphine. The results suggest that the

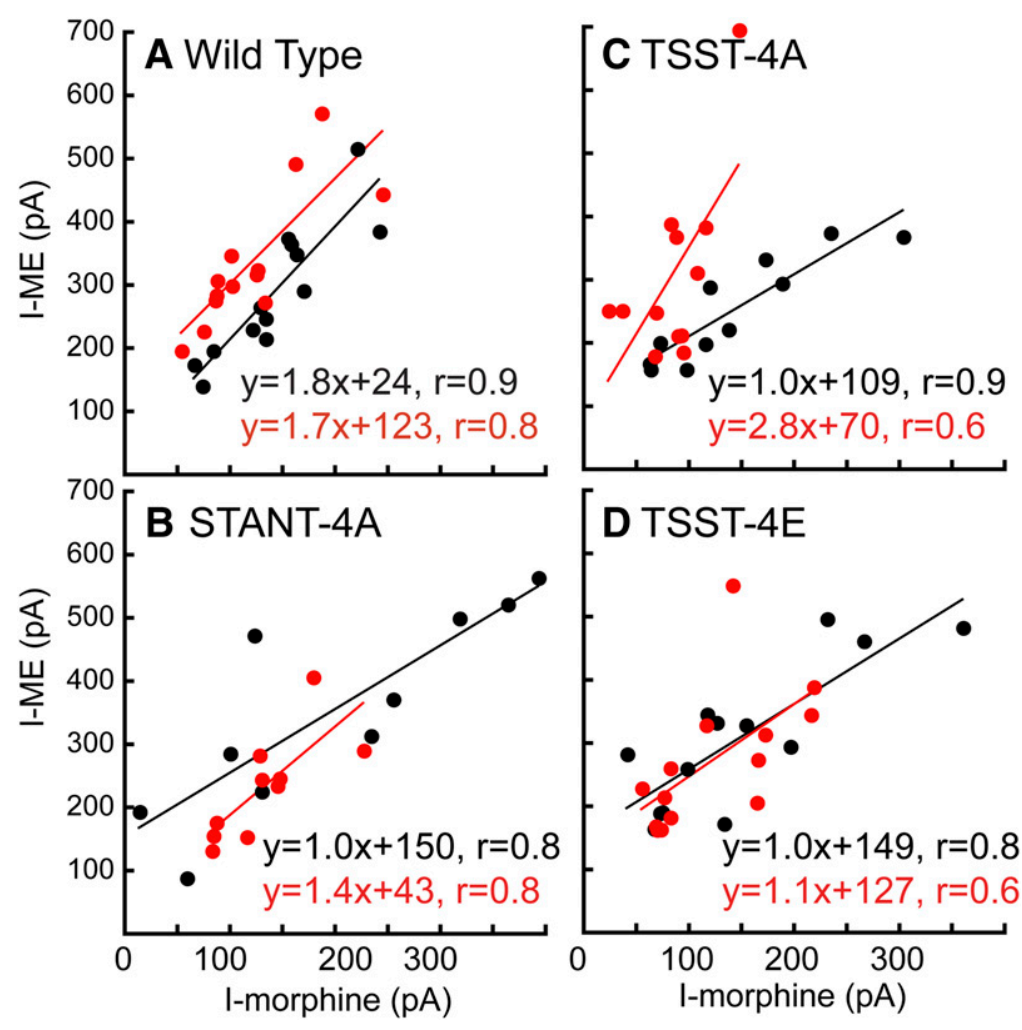

Fig. 3. Summary of results comparing the current induced by morphine $(1 \mu \mathrm{M})$ plotted against the current induced by $\mathrm{ME}$ $(30 \mu \mathrm{M})$ in individual cells in slices from untreated (black) and morphine-treated (red) animals. (A) Cells in slices taken from wild-type animals. The current induced by morphine after treatment with morphine is smaller than that in untreated animals. (B) Cells taken from animals after expression of the STANT mutant. (C) Cells taken from animals after expression of the TSST-4A mutant. (D) Cells in slices taken from animals expressing the TSST-4E mutant. 


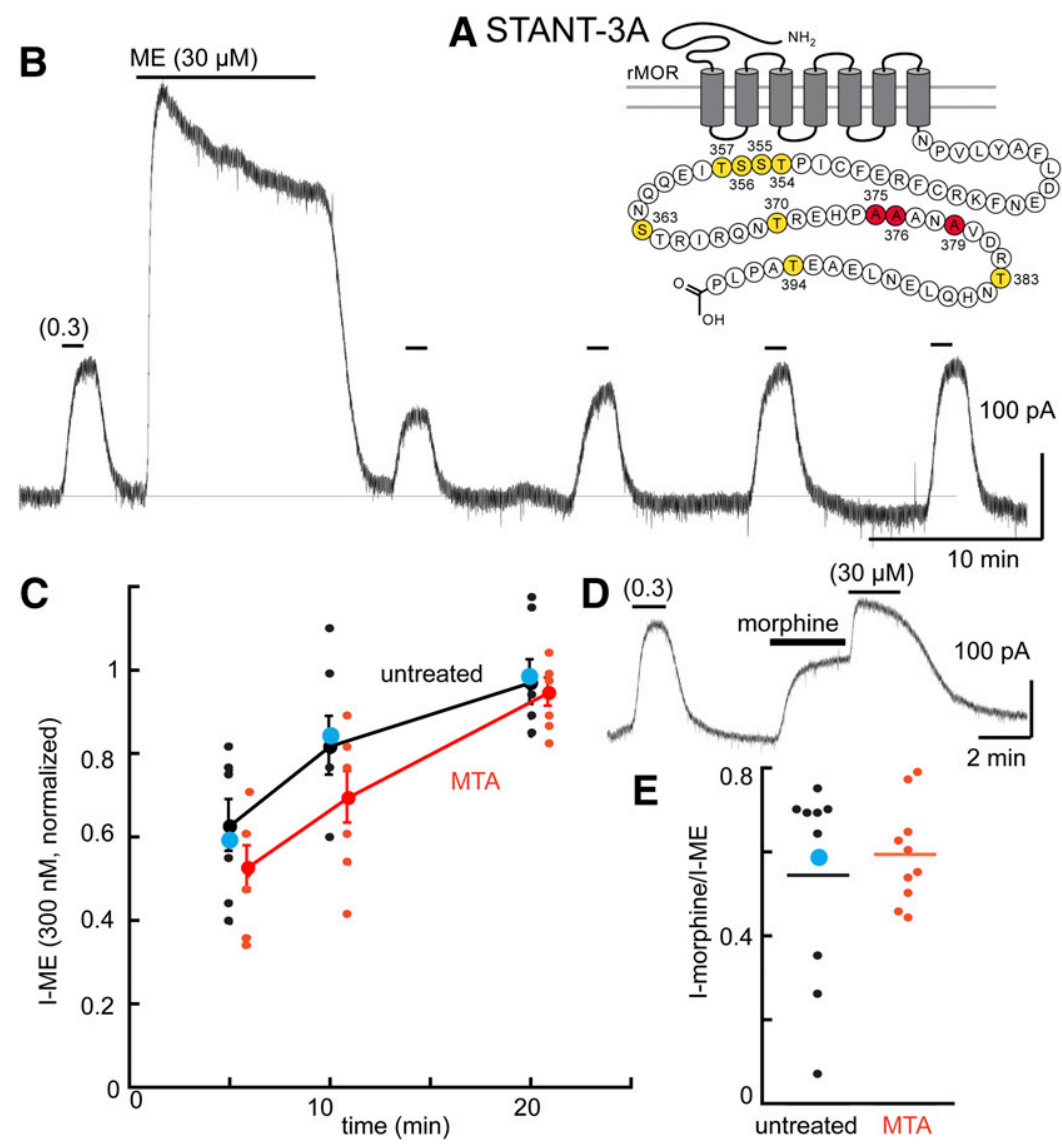

Fig. 4. Desensitization is decreased, and tolerance is blocked in cells expressing the STANT mutant receptor. (A) Snake plot illustrates the sites in the STANT mutant having alanine mutations (red, S375. T376, T379). (B) An experiment taken from an MTA illustrating the desensitization and recovery from desensitization of $\mathrm{ME}(0.3 \mu \mathrm{M})$. (C) Summary of results showing the recovery from desensitization in slices from untreated and MTAs. Blue dot indicates the results taken from the trace in (B). (D) Trace illustrating the morphine $(1 \mu \mathrm{M})$ current relative to the $\mathrm{ME}(30 \mu \mathrm{M})$ current. Blue dot indicates the result from the experiment illustrated in (D). (E) Summary of experiments plotting the current induced by morphine $(1 \mu \mathrm{M})$ divided by that induced by $\mathrm{ME}(30 \mu \mathrm{M}$, I-morphine/I-ME), indicating that the relative morphine current was unchanged in slices from MTAs. Untreated $0.55 \pm 0.23$, MTA $0.59 \pm 0.12(95 \%$ confidence level).

four remaining phosphorylation sites (TSST) play a role in the mechanisms induced by chronic morphine treatment.

TSST-4A. Acute desensitization and trafficking of this receptor closely resembled that measured in slices from wild-type animals and experiments with wild-type receptors expressed in the knockout animals (Figs. 1 and 6). After chronic morphine treatment, the decline from the peak current induced by $\mathrm{ME}$ ( $30 \mu \mathrm{M}, 10$ minutes) was not different from slices from untreated animals (untreated $0.53 \pm 0.13$ of the peak, $n=7$; MTAs $0.60 \pm 0.05$ of the peak $n=5$ ). No difference was noted in the decrease in the $\mathrm{ME}(0.3 \mu \mathrm{M})$ current or the time course or extent of recovery from desensitization after washout of the saturating concentration of ME (Fig. 6, B and C). Thus, by one measure (acute desensitization), chronic morphine had no effect; however, the current induced by morphine (morphine/ME) was reduced in slices taken from MTAs (Fig. 6, D and E). Thus, the second measure of tolerance was the same as that measured in slices taken from morphine-treated wild-type animals (compare Fig. 2E and Fig. 6E), suggesting that the link between acute desensitization and the reduced sensitivity to morphine was broken.

TSST-4E. Previous work has suggested that, by mimicking phosphorylation of the TSST sequence with glutamic acid residues (TSST-4E), a desensitized state of the receptor was induced (Birdsong et al., 2015). The initial current amplitude induced by $\mathrm{ME}(0.3 \mu \mathrm{M})$ was not different from cells expressing TSST-4A or wild-type receptors (TSST-4E $=286 \pm 102 \mathrm{pA}$, $n=7$, WT $=279 \pm 96, n=7$, Table $1, P>0.05$, ANOVA, Dunnett's post hoc). Likewise, the current induced by a saturating concentration of ME $(30 \mu \mathrm{M})$ was not different (TSST-4E $=400 \pm$ $123 \mathrm{pA}, n=10$ : WT $451 \pm 95 \mathrm{pA}, n=7$, Table $1, P>0.05$, ANOVA, Dunnett's post hoc). The decline from the peak current induced by $\mathrm{ME}(30 \mu \mathrm{M})$ was greater in slices from MTAs than in untreated controls (Fig. 7D; Table $1 P<0.05$, unpaired $t$ test). The current induced by $\mathrm{ME}(0.3 \mu \mathrm{M})$ after washing of the saturating concentration of $\mathrm{ME}(30 \mu \mathrm{M})$ was also smaller in slices from MTAs than in untreated controls (Fig. 7D; Table 1, $P<0.05$, unpaired $t$ test). Finally, receptor internalization induced by $\mathrm{ME}$ (30 $\mu \mathrm{M}, 10$ minutes) was similar to that measured in wild-type and TSST-4A receptors (Fig. 1).

The results indicate that acute desensitization of the TSST$4 \mathrm{E}$ receptors in slices from MTAs is facilitated, but recovery from desensitization is complete (Fig. 7C; Table 1). Finally, the plot of morphine versus ME current amplitudes illustrates the overlap in experiments in slices from untreated and MTAs (Fig. 3E, $P>0.05$, unpaired $t$ test). Although acute desensitization was increased in slices taken from MTAs, recovery was complete, and no change occurred in the current induced by morphine, suggesting that one measure of tolerance of these receptors was blocked, but acute desensitization was facilitated. As with the results obtained with the TSST-4A receptors, acute desensitization and tolerance appear to be dependent on separate processes.

\section{Discussion}

The present study measured the opioid-induced outward current mediated by G-protein coupled inwardly rectifying potassium channels to examine the functional regulation of 

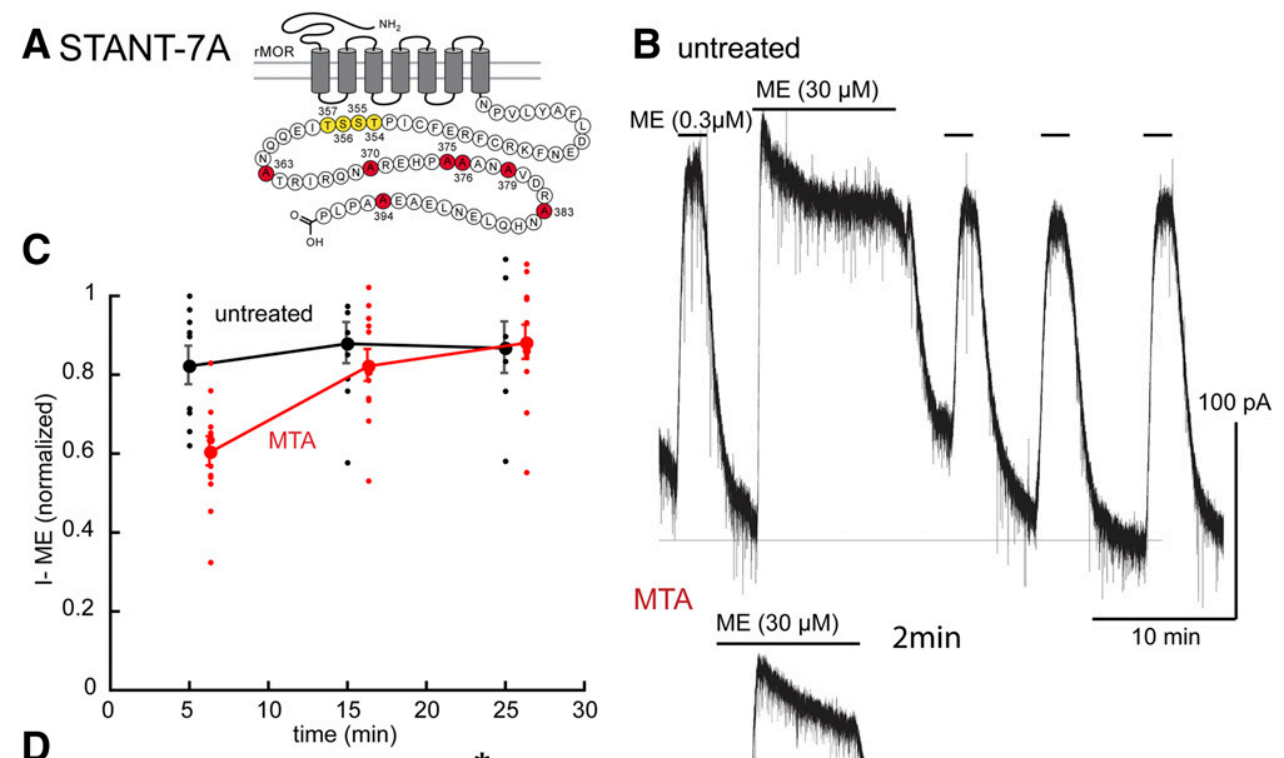

Fig. 5. Transient desensitization is induced fafter chronic morphine treatment in the STANT-7A mutant receptors. (A) Snake plot indicates the site (red, S363, T370, S375, T376, T379, T383, and T394) with alanine mutations. (B) Illustrates the lack of $\mathrm{ME}$ induced desensitization in a slice from an untreated animal (top) and a morphine-treated (bottom) animal. (C) Summary of results showing the transient desensitization induced by chronic morphine treatment (MTAs, red). (D) Left: Decline from the peak current during $\mathrm{ME}(30 \mu \mathrm{M}, 10$ minutes) in slices from untreated (black) and morphine-treated (red) animals. Right shows the ME $(0.3 \mu \mathrm{M})$ current relative to the peak ME $(30 \mu \mathrm{M})$ current in slices from untreated and morphine treated animals. $* P<0.05$.
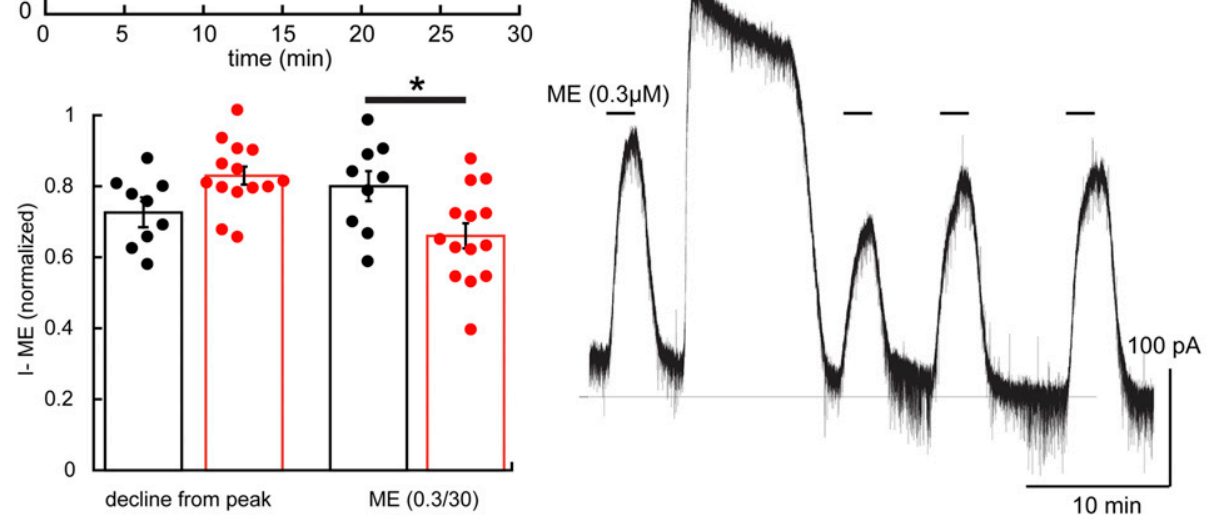

MORs by phosphorylation sites on the $\mathrm{C}$ terminus. Alanine mutation of all phosphorylation sites (11S/T-A) on the C terminus results in a dramatic decrease in acute desensitization and long-term tolerance to opioids (Arttamangkul et al., 2018; Kliewer et al., 2019). The present study used a series of MORs having selective alanine mutations in different areas of the $\mathrm{C}$ terminus to determine the role of acute desensitization in the development of long-term tolerance. The results show that each of the mutated receptors affected one or another aspect of MOR signaling. With one exception (STANT-7A), some degree of acute desensitization was present in all receptors, and after chronic morphine treatment, an acute, although transient, desensitization of even that receptor occurred. The unexpected observation was that, by using three measures of opioid action to determine the level of tolerance, there were distinct differences between the mutant opioid receptors. Thus, different phosphorylation sites on the $\mathrm{C}$ terminus have functionally distinct actions after chronic morphine treatment.

\section{Acute Desensitization as a Measure of Tolerance}

After chronic treatment of animals with morphine, acute desensitization was augmented, and recovery from desensitization was prolonged (Dang and Williams, 2004; Quillinan et al., 2011; Arttamangkul et al., 2018). Acute desensitization was facilitated in slices expressing TSST-4E as in wildtype animals but not in STANT-3A, TSST-4A MOR variants. There was a transient facilitation in the STANT-7A variants, but that is because there was no desensitization in slices from untreated animals, and the increase in desensitization was small, transient, and to the same level as in the STANT$3 \mathrm{~A}$ variants. Unlike the observation made in wild-type animals, the delayed time course of recovery after chronic morphine treatment was not present in any of the mutated receptors. It therefore appears that each of the phosphorylation sites on the $\mathrm{C}$ terminus is necessary for both the augmented acute desensitization and slowed recovery from desensitization that is induced after chronic morphine treatment. Thus, the full complement of phosphorylation sites appears necessary for development of long-term tolerance.

\section{Uncoupling of Signaling as a Measure of Long-Term Tolerance}

As a partial agonist, morphine offers a sensitive assay for functional coupling (Christie et al., 1987; Dang and Williams, 2004; Levitt and Williams, 2012; Williams, 2014). In slices taken from animals treated chronically with morphine, the morphine-induced current was reduced (Christie et al., 1987; Quillinan et al., 2011). This measure of long-term tolerance was present in some but not all the mutant MORs tested. With the notable exception of TSST-4E, the MOR mutations that blocked desensitization and internalization (STANT3A, STANT-7A, and total phosphorylation deficient (Arttamangkul et al., 2018) also blocked the decrease in the morphine-induced current. 

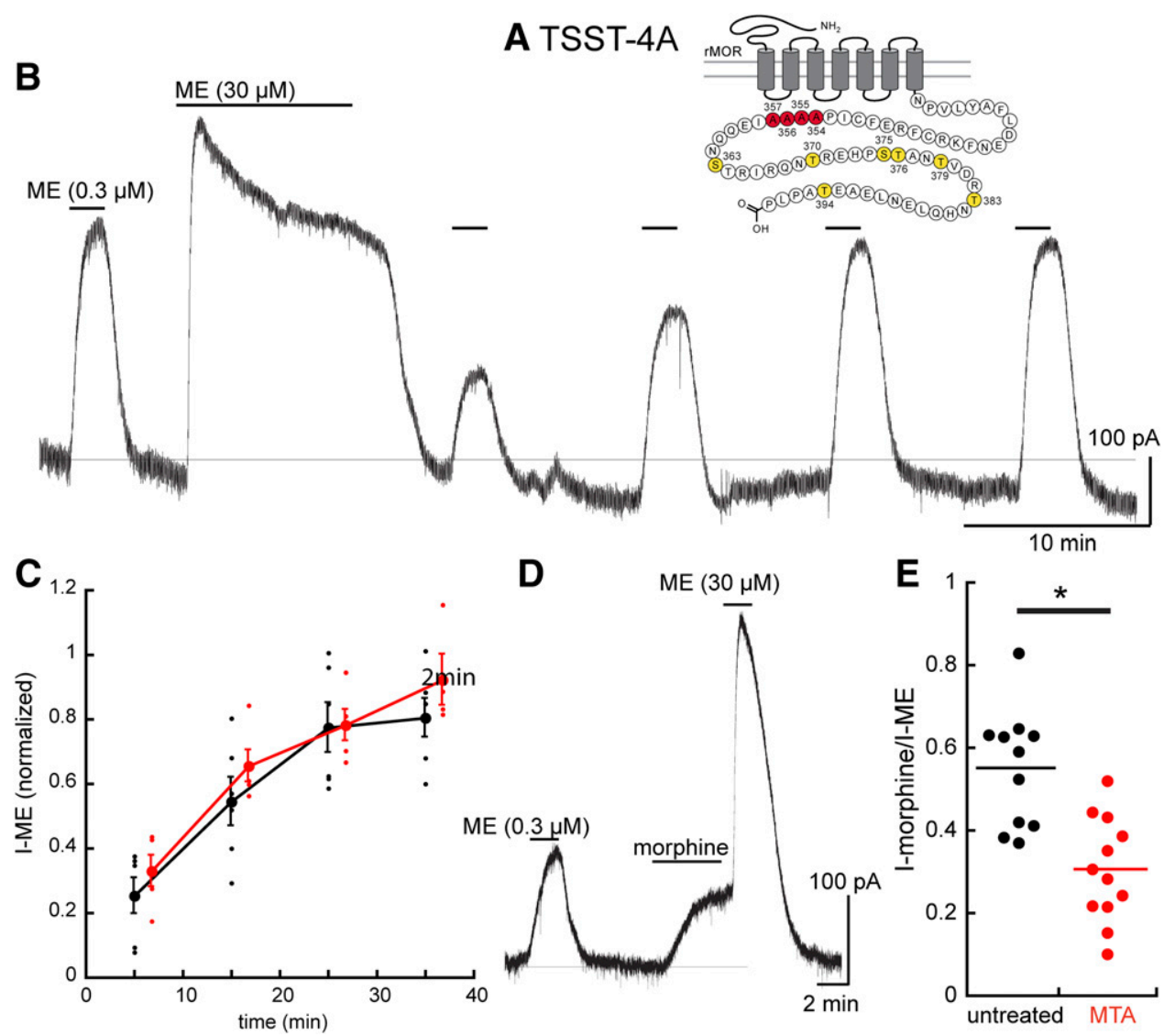

Fig. 6. The TSST-4A mutant receptors distinguish tolerance measured by two assays, the increase in acute desensitization (blocked), and the decrease in sensitivity to morphine (present). (A) Snake plot illustrating the sites that were mutated to alanine (red, T354, S355, S356. T357). (B) An experiment illustrating the acute desensitization and recovery from desensitization. (C) Summarized results showing the recovery from desensitization in untreated (black) and MTAs (red). Acute desensitization is insensitive to chronic morphine treatment. (D) An experiment in a slice taken from an MTA illustrating the decreased amplitude of the current induced by morphine. (E) Dot plot shows the relative current induced by morphine (I-morphine/I-ME) in slices from untreated (black) and morphinetreated (red) animals, indicating that the relative morphine current was lower in slices taken from MTAs. Untreated 0.55 \pm 0.14 , MTAs $0.30 \pm 0.13$ (95\% confidence level). ${ }^{*} P<0.05$

\section{Phosphorylation Cassettes}

It is well established that alanine mutations in the STANT-3A sequence decreases arrestin recruitment and receptor internalization (Lau et al., 2011; Just et al., 2013). Measures of tolerance after chronic morphine were also blocked in receptors with the STANT-3A and STANT-7A mutations (this study).

Much less in known about how alanine mutations of the TSST sequence affect MOR function, particularly after chronic morphine treatment. The TSST-4A receptors desensitize and internalize "normally" with agonist application. A receptorbinding assay that used a fluorescently labeled agonist, DERM-A594, in human embryonic kidney cells was used to measure the change in agonist affinity after incubation with potent agonists, such as ME (Birdsong et al., 2013). A significant long-term ( 1 to 2 hours) increase in agonist affinity followed incubation for 20-120 minutes. The increased affinity was not affected after treatment with pertussis toxin and was present in arrestin $2 / 3$ knock out cells, and there was no change in antagonist affinity. The increase in agonist affinity was blunted in the TSST-4A receptors, particularly with longer agonist incubation times. The results suggested that phosphorylation of the TSST sequence largely blocked one consequence of acute agonist desensitization. Glutamate substitutions in the TSST sequence (TSST-4E) increased agonist affinity in the absence of preincubation, suggesting that the glutamate substitution largely mimicked the effect of phosphorylation of this sequence (Birdsong et al., 2013).

Previous work reported that two components of tolerance were induced by chronic morphine treatment, one that was transient (60-90 minutes) and a second that was long- term (>3 hours) (Levitt and Williams, 2012). The striking difference between the TSST-4A and TSST-4E receptor function after chronic morphine treatment suggests an important role for these phosphorylation sites in the adaptive changes induced by chronic morphine treatment. Although the idea that acute desensitization and tolerance are intimately linked is generally supported, the results indicate that disruption of the normal role of this (i.e., TSST) sequence distinguishes the two processes. After chronic morphine treatment, long-term tolerance, as measured by the decrease in the current induced by morphine, was maintained with the TSST-4A mutants. There was, however, no decrease in the current induced by morphine in the TSST-4E mutants in slices taken from MTAs. Thus, this measure of long-term tolerance to morphine was blocked. The adaptive changes in acute desensitization were different in that acute desensitization after chronic morphine treatment was increased in the TSST-4E receptors, as in wildtype receptors. On the other hand, acute desensitization of the TSST-4A receptors was unchanged by chronic morphine treatment. The present results could result from two separate mechanisms that underlie acute desensitization, as previously indicated (Dang et al., 2009).

\section{Summary}

Alanine mutations of different phosphorylation sites on the $\mathrm{C}$ terminus were used to identify receptor-dependent signaling by measuring acute desensitization, recovery from desensitization, and internalization. Mutations of the STANT 


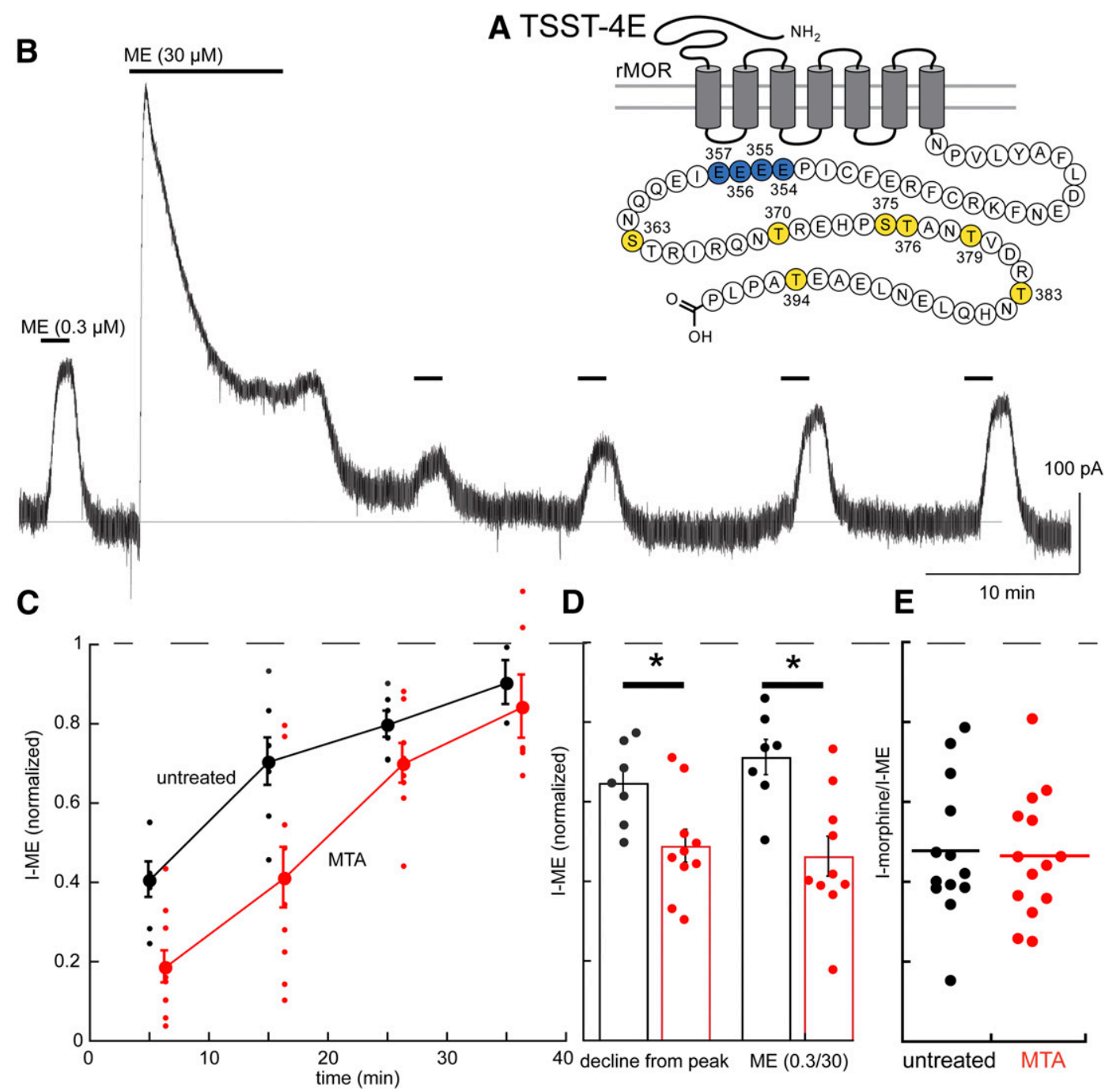

Fig. 7. After chronic treatment with morphine, the TSST-4E mutant MOR separates induction of changes in acute desensitization (present) from the decrease in the sensitivity to morphine (blocked). (A) Snake plot shows the sites with glutamate substitutions (blue, T354, S355, S356. T357). (B) An example of acute ME-induced desensitization and recovery from desensitization in a slice from an MTA. (C) Summary of experiments showing recovery from desensitization in slices from untreated (black) and MTAs (red). (D) Summarized results showing the decline from the peak current induced by ME (30 $\mu \mathrm{M}, 10$ minutes) and the amplitude of the $\mathrm{ME}(0.3 \mu \mathrm{M})$ current relative to the peak current induced by ME $(30 \mu \mathrm{M})$ in slices from untreated and MTAs. (E) Dot plot of the relative current induced by morphine $(1 \mu \mathrm{M})$ relative to the peak current induced by $\mathrm{ME}(30 \mu \mathrm{M}$, I-morphine/I-ME) showing that there was no change in the relative morphine current between slices from untreated and MTAs (untreated $0.48 \pm 0.18$, MTA $0.47 \pm 0.16,95 \%$ confidence level). ${ }^{*} P<0.05$.

sequence blocked all three measures as well as measures of tolerance. Mutations in the TSST sequence had little effect on acute actions but had a modulatory effect on the expression of tolerance.

\section{Acknowledgments}

We thank Drs. Brooks Robinson and Erica Levitt for helpful discussion and feedback during manuscript preparation.

\section{Authorship Contributions}

Participated in research design: Arttamangkul, Birdsong, Williams.

Conducted experiments: Arttamangkul, Leff, Koita, Williams.

Contributed new reagents or analytic tools: Arttamangkul.

Performed data analysis: Williams.

Wrote or contributed to writing of the manuscript: Arttamangkul, Birdsong, Williams.

Note Added in Proof-NIH Grant numbers JTW RO1 DA08163, WTB DA043779, ERL T32DAD07262 were accidentally not included in the Fast Forward version published August 5, 2019. The funding footnote has now been corrected.

\section{References}

Arttamangkul S, Heinz DA, Bunzow JR, Song X, and Williams JT (2018) Cellular tolerance at the $\mu$-opioid receptor is phosphorylation dependent. eLife 7 :e343989. Birdsong WT, Arttamangkul S, Bunzow JR, and Williams JT (2015) Agonist binding and desensitization of the $\mu$-opioid receptor is modulated by phosphorylation of the C-terminal tail domain. Mol Pharmacol 88:816-824.

Birdsong WT, Arttamangkul S, Clark MJ, Cheng K, Rice KC, Traynor JR, and Williams JT (2013) Increased agonist affinity at the $\mu$-opioid receptor induced by prolonged agonist exposure. J Neurosci 33:4118-4127.

Chen YJ, Oldfield S, Butcher AJ, Tobin AB, Saxena K, Gurevich VV, Benovic JL, Henderson G, and Kelly E (2013) Identification of phosphorylation sites in the $\mathrm{COOH}$-terminal tail of the $\mu$-opioid receptor. $J$ Neurochem 124:189-199.

Christie MJ, Williams JT, and North RA (1987) Cellular mechanisms of opioid tolerance: studies in single brain neurons. Mol Pharmacol 32:633-638.

Dang VC, Napier IA, and Christie MJ (2009) Two distinct mechanisms mediate acute mu-opioid receptor desensitization in native neurons. J Neurosci 29:3322-3327.

Dang VC and Williams JT (2004) Chronic morphine treatment reduces recovery from opioid desensitization. J Neurosci 24:7699-7706.

Doll C, Konietzko J, Pöll F, Koch T, Höllt V, and Schulz S (2011) Agonist-selective patterns of $\mu$-opioid receptor phosphorylation revealed by phosphosite-specific antibodies. Br J Pharmacol 164:298-307. 
Just S, Illing S, Trester-Zedlitz M, Lau EK, Kotowski SJ, Miess E, Mann A, Doll C, Trinidad JC, Burlingame AL, et al. (2013) Differentiation of opioid drug effects by hierarchical multi-site phosphorylation. Mol Pharmacol 83: 633-639.

Kliewer A, Schmiedel F, Sianati S, Bailey A, Bateman JT, Levitt ES, Williams JT, Christie MJ, and Schulz S (2019) Phosphorylation-deficient G-protein-biased $\mu$-opioid receptors improve analgesia and diminish tolerance but worsen opioid side effects. Nat Commun 10:367.

Lau EK, Trester-Zedlitz M, Trinidad JC, Kotowski SJ, Krutchinsky AN, Burlingame AL, and von Zastrow M (2011) Quantitative encoding of the effect of a partial agonist on individual opioid receptors by multisite phosphorylation and threshold detection (Abstract). Sci Signal 4:ra52

Levitt ES and Williams JT (2012) Morphine desensitization and cellular tolerance are distinguished in rat locus ceruleus neurons. Mol Pharmacol 82 983-992.

Miess E, Gondin AB, Yousuf A, Steinborn R, Mösslein N, Yang Y, Göldner M, Ruland JG, Bünemann M, Krasel C, et al. (2018) Multisite phosphorylation is required for sustained interaction with GRKs and arrestins during rapid $\mu$-opioid receptor desensitization. Sci Signal 11:1-15.

Pologruto TA, Sabatini BL, and Svoboda K (2003) ScanImage: flexible software for operating laser scanning microscopes. Biomed Eng Online 2:13.
Quillinan N, Lau EK, Virk M, von Zastrow M, and Williams JT (2011) Recovery from mu-opioid receptor desensitization after chronic treatment with morphine and methadone. $J$ Neurosci 31:4434-4443.

Wang HL, Chang WT, Hsu CY, Huang PC, Chow YW, and Li AH (2002) Identification of two C-terminal amino acids, Ser(355) and Thr(357), required for short-term homologous desensitization of mu-opioid receptors. Biochem Pharmacol 64:257-266.

Williams JT (2014) Desensitization of functional $\mu$-opioid receptors increases agonist off-rate. Mol Pharmacol 86:52-61.

Williams JT, Ingram SL, Henderson G, Chavkin C, von Zastrow M, Schulz S, Koch T, Evans CJ, and Christie MJ (2013) Regulation of $\mu$-opioid receptors: desensitization, phosphorylation, internalization, and tolerance. Pharmacol Rev 65:223-254.

Williams JT and North RA (1984) Opiate-receptor interactions on single locus coeruleus neurones. Mol Pharmacol 26:489-497.

Yousuf A, Miess E, Sianati S, Du YP, Schulz S, and Christie MJ (2015) Role of phosphorylation sites in desensitization of $\mu$-opioid receptor. Mol Pharmacol 88:825-835.

Address correspondence to: John T. Williams, Vollum Institute L474, Oregon Health \& Science University, 3181 SW Sam Jackson Park Rd., Portland, OR 97239. E-mail: williamj@ohsu.edu 